\title{
PENGARUH KEPERCAYAAN DAN KEPUASAN KERJA TERHADAP KINERJA PELAYANAN MAHASISWA DI UNIVERSITAS MUSLIM MAROS
}

\author{
Ummul Chair \\ Fakultas Ekonomi dan Bisnis Universitas Muslim Maros
}

\begin{abstract}
Abstrak : Tujuan penelitian ini adalah menganalisis pengaruh kepercayaan dan kepuasan kerja terhadap kinerja pelayanan mahasiswa di Universitas Muslim Maros. Penelitian ini dilaksanakan di Fakultas Ekonomi dan Bisnis, Fakultas Pertanian, Peternakan dan Kehutanan, dan Fakultas Keguruan dan Ilmu Pendidikan Universitas Muslim Maros. Jenis dan sumber data yang digunakan adalah data primer dan sekunder. Teknik pengumpulan data adalah observasi dan wawancara. Populasi penelitian ini adalah mahasiswa semester 6 (Enam) Tahun Akademik 2018/2019 di ketiga fakultas tersebut. Sampel mahasiswa diambil secara proporsional pada masingmasing ketiga fakultas dengan metode proportional random sampling. Analisis yang digunakan adalah analisis data kuantitatif dan regresi berganda dengan menggunakan skala Likert. Hasil penelitian menunjukkan bahwa kepercayaan dan kepuasan kerja secara bersama-sama berpengaruh nyata terhadap kinerja pelayanan mahasiswa di Universitas Muslim Maros.
\end{abstract}

Keyword : Kepercayaan, Kepuasan Kerja, Kinerja Pelayanan

\section{PENDAHULUAN}

Seiring meningkatnya kebutuhan masyarakat terhadap pendidikan formal, khususnya pendidikan tinggi, menjadikan perguruan tinggi sebagai wadah yang penting untuk dapat menghasilkan sumber daya manusia yang berkualitas. Untuk dapat unggul dalam persaingan itu, sebuah perguruan tinggi harus meningkatkan mutu pendidikan dan kualitas lembaga. Sebuah lembaga dikatakan berkualitas apabila memberikan pelayanan yang berkualitas, yang dapat memenuhi kebutuhan mahasiswa akan informasi mengenai pendidikan di lembaga itu (Mardah, 2018). Membangun pemasaran PT 
guna meningkatkan daya saing sumber daya manusia perlu dikerjakan oleh semua pihak, baik oleh pemerintah, PT, masyarakat dan dunia usaha perlu ikut ambil andil dalam pengembangan dunia pendidikan tinggi (Ambartiasari dkk, 2017).

Kepercayaan adalah keyakinan bahwa seseorang akan menemukan yang diinginkan pada mitra pertukaran. Kepercayaan melibatkan kesediaan seseorang untuk bertingkah laku, karena keyakinan bahwa mitranya akan memberikan diharapkan dan suatu harapan yang umumnya dimiliki seseorang bahwa kata, janji atau pernyataan orang lain dapat dipercaya (Edastama, 2014). Kepercayaan adalah suatu kemauan atau keyakinan mitra pertukaran untuk menjalin hubungan jangka panjang untuk menghasilkan kerja yang positif (Arifin, 2011). Kepercayaan dalam pemasaran jasa lebih menekankan pada sikap individu yang mengacu keyakinan konsumen atas kualitas dan keterandalan jasa yang diterimanya. Semakin kuat kepercayaan pelanggan terhadap penyedia jasa, maka selain memperkuat dorongan atau motivasi untuk mempertahankan hubungan, juga memperkuat kecenderungan untuk melakukan pembelian ulang atau sikap positif terhadap perusahaan (Suyanto dan Setiawan, 2019).

Kepuasan kerja merupakan sesuatu yang bersifat individual. Setiap individu memilki tingkat kepuasan yang berbeda sesuai dengan sistem nilai yang berlaku pada dirinya. Kepuasan kerja adalah keadaan emosional karyawan yang menyenangkan atau tidak menyenangkan terhadap tugas atau pekerjaan yang telah dibebani (Zahara dan Hidayat, 2017). Pada dasarnya kualitas pelayanan dipengaruhi oleh jasa yang dirasakan dengan jasa yang diharapkan. Untuk mendapatkan kepuasan pelanggan maka perusahaan harus berusaha agar jasa yang dirasakan pelanggan adalah lebih besar daripada yang diharapkan (Safiuddin dan Sunarsih, 2016). Kepuasan dan ketidakpuasan pelanggan adalah respon pelanggan terhadap evaluasi ketidaksesuaian yang dirasakan antara harapan sebelumnya dan kinerja aktual produk yang dirasakan setelah pemakaiannya (Dafroyati, 2016).

Semakin tinggi kualitas pelayanan administrasi akademik semakin tinggi pula kepuasan mahasiswa. Untuk menciptakan kepuasan kepada mahasiswa maka perlu ditingkatkan kinerja dari karyawan atau staf akademik (Santhi dan Hartati, 2017). Aspek layanan akademik, pelayanan dan kinerja dosen sebagai salah satu indikator kunci dalam memenuhi konsep kepuasan mahasiswa sebagai pengguna jasa perguruan tinggi. Pengukuran mutu pelayanan merupakan elemen penting dalam menyediakan pelayanan yang lebih baik, lebih efisien, dan lebih efektif. Oleh karena itu, mutu pelayanan harus dimulai dari kebutuhan konsumen akan pelayanan dan berakhir pada persepsi konsumen (C) 2020 STIE TDN. All rights reserved

Corresponding Author: 
merusak hubungan jangka panjang (Suyanto dan Setiawan, 2019).

\section{Kepuasan Kerja}

Kepuasan kerja merupakan sesuatu yang bersifat individual. Setiap individu memilki tingkat kepuasan yang berbeda sesuai dengan sistem nilai yang berlaku pada dirinya. Kepuasan kerja adalah keadaan emosional karyawan yang menyenangkan atau tidak menyenangkan terhadap tugas atau pekerjaan yang telah dibebani. Kepuasan kerja adalah sikap umum terhadap pekerjaan seseorang yang menunjukkan perbedaan antara jumlah penghargaan yang diterima pekerja dan jumlah seharusnya mereka terima (Zahara dan Hidayat, 2017). Kepuasan kerja adalah sikap emosional karyawan terhadap pekerjaan dengan membandingkan jumlah hasil yang diterima dan jumlah yang seharusnya diterima.

\begin{tabular}{lcr}
\multicolumn{2}{c}{ Pengetahuan } & tentang \\
kepuasan & mahasiswa & akan \\
memberikan & banyak & manfaat.
\end{tabular}
Manfaat tersebut antara lain: kepuasan mahasiswa berfungsi sebagai pedoman untuk mengarahkan seluruh organisasi ke arah pemenuhan kebutuhan mahasiswa sehingga menjadi sumber dari keunggulan daya saing yang berkelanjutan (Bhakti dan Rahmawati, 2017). Kunci untuk memberikan kualitas pelayanan yang lebih baik adalah memenuhi atau melebihi ekspektasi kualitas pelayanan pelanggan sasaran. Kualitas pelayanan digambarkan sebagai suatu pernyataan tentang sikap, hubungan yang dihasilkan dari perbandingan dari ekspektasi dengan kinerja (Santhi dan Hartati, 2017).

\section{Kinerja Pelayanan}

Kinerja adalah kesediaan seseorang atau kelompok orang untuk melakukan sesuatu kegiatan dan menyempurnakannya sesuai dengan tanggung jawabnya dengan hasil seperti yang diharapkan (Dedeh, 2017). Kinerja merupakan hasil pekerjaan yang mempunyai hubungan kuat dengan tujuan strategis organisasi, kepuasan konsumen, dan memberikan kontribusi pada ekonomi. Kinerja merupakan hasil pekerjaan yang mempunyai hubungan kuat dengan tujuan strategis organisasi. Tinggi rendahnya kinerja pegawai berkaitan erat dengan ketercapaian tujuan organisasi (Kawulur, 2017). Kinerja merupakan hasil kerja secara kualitas dan kuantitas yang dicapai seorang karyawan dalam melaksanakan tugasnya sesuai dengan tanggung jawab yang diberikan kepadanya. Kinerja merupakan hasil kerja karyawan yang dapat diamati dan dapat diukur (Zahara dan Hidayat, 2017).

Kinerja disebut sebagai prestasi kerja adalah hasil kerja secara kuantitas dan kualitas yang dicapai seseorang dalam melaksanakan tugas sesuai tanggung jawab yang diberikan pada waktu tertentu. Kinerja dalam menjalankan fungsinya tidak berdiri sendiri, tapi berhubungan dengan kepuasan kerja dan tingkat imbalan, dipengaruhi oleh keterampilan, kemampuan dan sifat-sifat individu (Nyavon, 2017). Kinerja merupakan prestasi kerja

Corresponding Author: 
yakni perbandingan antara hasil kerja yang secara nyata dengan standar kerja yang ditetapkan. Setiap organisasi berusaha untuk meningkatkan kinerja karyawannya demi tercapainya tujuan yang telah ditetapkan oleh organisasi (Sutrisno dan Maryono, 2016).

\section{Hipotesis}

Berdasarkan latar belakang, rumusan masalah dan tujuan penelitian, maka hipotesis dalam penelitian ini adalah kepercayaan dan kepuasan kerja berpengaruh nyata terhadap kinerja pelayanan mahasiswa di Universitas Muslim Maros

\section{METODE PENELITIAN}

Penelitian ini dilaksanakan di Fakultas Ekonomi dan Bisnis, Keguruan dan Ilmu Pendidikan, dan Fakultas Pertanian, Peternakan dan Kehutanan Universitas Muslim Maros. Jenis dan sumber data yang digunakan adalah data primer dan sekunder. Teknik pengumpulan data adalah observasi dan wawancara. Populasi penelitian ini adalah mahasiswa semester 6 (Enam) TA 2018/2019 di ketiga fakultas tersebut. Jumlah sampel mahasiswa yang diambil adalah 100 orang. Sampel mahasiswa diambil secara proporsional pada masing-masing ketiga fakultas dengan metode proportional random sampling.

Analisis yang digunakan adalah analisis data kuantitatif dan regresi berganda dengan menggunakan skala Likert yang diperoleh dari daftar pertanyaan yang digolongkan ke dalam lima tingkatan (Sugyono, 2005) sebagai berikut.

1. Jawaban sangat tidak setuju $=1$

2. Jawaban tidak setuju $=2$

3. Jawaban netral $=3$

4. Jawaban setuju $=4$

5. Jawaban sangat setuju $=5$

Model analisis regresi ganda yang digunakan untuk menganalisis pengaruh kepercayaan dan kepuasan kerja terhadap kinerja pelayanan mahasiswa di Universitas Muslim Maros yaitu :

$Y=\beta_{0}+\beta_{1} \ln X_{1}+\beta_{2} \ln X_{2}+\mu$

Keterangan :

$$
\begin{array}{ll}
\mathrm{Y} & =\text { kinerja pelayanan } \\
\beta_{0} & =\text { intersept } \\
\beta_{1}, \beta_{2} & =\text { koefisien regresi } \\
\mu & =\text { error term } \\
\mathrm{X}_{1} & =\text { kepercayaan } \\
\mathrm{X}_{2} & =\text { kepuasan kerja }
\end{array}
$$

\section{HASIL PENELITIAN DAN PEMBAHASAN}

Pengaruh Kepercayaan dan Kepuasan Kerja Terhadap Kinerja Pelayanan Mahasiswa

Pengaruh kepercayaan dan kepuasan kerja terhadap kinerja pelayanan mahasiswa di Universitas Muslim Maros dianalisis dengan menggunakan analisis regresi ganda. Hasil analisis regresi tersebut disajikan pada Tabel 1. 
Tabel 1. Hasil Analisis Regresi Kepercayaan dan Kepuasan Kerja Terhadap Kinerja Pelayanan Mahasiswa di Universitas Muslim Maros

\begin{tabular}{ccrrrrr}
\hline Variabel & $\begin{array}{c}\text { Tanda } \\
\text { Harapan }\end{array}$ & $\begin{array}{c}\text { Koefisien } \\
\text { Regresi }\end{array}$ & $\begin{array}{c}\text { Standar } \\
\text { Eror }\end{array}$ & t-hitung & Prob. & Signifikan \\
\hline $\mathrm{C}$ & $+/-$ & 18,610 & 1,726 & 10,783 & 0,000 & $* * *$ \\
$\mathrm{X}_{1}$ & + & 0,317 & 0,063 & 5,018 & 0,000 & $* * *$ \\
$\mathrm{X}_{2}$ & + & 0,564 & 0,060 & 9,393 & 0,000 & $* * *$ \\
\hline $\mathrm{R}^{2}$ & 0,992 & $* * *$ & Signifikan pada & tingkat & Kesalahan \\
R-squared & 0,984 & \multicolumn{2}{c}{$1 \%$} & & \\
S.E. of regression & 1,538 & & & \\
F-statistik & $3.048,0 * * *$ & & & \\
\hline
\end{tabular}

Sumber : Data primer diolah, 2020

Berdasarkan hasil analisis pada Tabel 1, diketahui bahwa nilai koefisien determinasi $\left(\mathrm{R}^{2}\right)$ sebesar 0,992 . Hal ini berarti sebanyak 99,20 persen variasi dari variabel kinerja pelayanan dapat dijelaskan oleh variabel independen dalam model yaitu variabel kepercayaan dan variabel kepuasan kerja. Hasil uji menunjukkan bahwa nilai $\mathrm{F}$ hitung $(\alpha: 1 \%)$, sebesar 3.048,0 lebih besar dari $\mathrm{F}$ tabel $(5,05)$ berarti bahwa variabel independen (kepercayaan dan kepuasan kerja) secara bersamasama berpengaruh nyata terhadap kinerja pelayanan pada mahasiswa.

Hasil uji t terhadap variabel independen menunjukkan variabel independen yang berpengaruh nyata terhadap kinerja pelayanan adalah kepercayaan $\left(\mathrm{X}_{1}\right)$ dan kepuasan kerja $\left(\mathrm{X}_{2}\right)$. Koefisien regresi variabel kepercayaan dan variabel kepuasan kerja bertanda positif. Berarti setiap penambahan faktor kinerja pelayanan mahasiswa akan menaikkan kinerja pelayanan pada mahasiswa.

\section{Kepercayaan $\left(X_{1}\right)$}

Koefisien

regresi

kepercayaan mempunyai koefisien regresi positif dan berpengaruh nyata terhadap kinerja pelayanan pada mahasiswa. Koefisien regresi kepercayaan sebesar 0,317, hasil uji t berpengaruh nyata pada tingkat kepercayaan 99 persen. Hal ini menunjukkan bahwa kepercayaan berpengaruh nyata terhadap kenaikan kinerja pelayanan. Berarti setiap kenaikan kepercayaan sebesar 1 persen akan menaikkan kinerja pelayanan pada mahasiswa sebesar 0,317 persen. Kepercayaan adalah sebagai kesediaan (willingness) individu untuk menggantungkan dirinya pada pihak lain yang terlibat dalam pertukaran karena individu mempunyai keyakinan (confidence) kepada pihak lain (Elrado dkk, 2014). Kepercayaan merupakan suatu kemauan atau keyakinan mitra pertukaran untuk menjalin hubungan jangka panjang untuk menghasilkan kerja yang positif (Sahanggamu dkk, 2015). Kepercayaan adalah ekspektasi yang dipegang oleh individu bahwa ucapan seseorang (C) 2020 STIE TDN. All rights reserved

Corresponding Author: 
dapat diandalkan. Kepercayaan dan kepuasan pelanggan merupakan sebuah perbandingan yang diharapkan pelanggan dengan yang telah diterima pelanggan (Guspul, 2014). Kepercayaan pelanggan yang tinggi akan dapat memberikan pengaruhnya terhadap kepuasan dan loyalitas pelanggan (Laely, 2016). Kepercayaan memegang peran penting dalam jalinan hubungan jangka panjang untuk mencapai kesetiaan pelanggan antara pelanggan dengan perusahaan terutama yang mencakup kepercayaan pelanggan mengenai kualitas, reliabilitas, integritas dari jasa yang disampaikan perusahaan (Nurhadi dan Azis, 2018). Sejalan dengan hasil penelitian Ambartiasari dkk (2017), kualitas pelayanan dalam hal ini kinerja pelayanan berpengaruh nyata dan positif terhadap kepuasan mahasiswa pada Politeknik Indonesia Venezuela. Demikian juga hasil penelitian Edastama (2014), kualitas pelayanan berpengaruh nyata terhadap tingkat kepercayaan mahasiswa pada perguruan tinggi swasta di Jakarta.

\section{Kepuasan Kerja $\left(\mathbf{X}_{2}\right)$}

Koefisien regresi kepuasan kerja mempunyai koefisien regresi positif dan berpengaruh nyata terhadap kinerja pelayanan pada mahasiswa. Koefisien regresi kepuasan kerja sebesar 0,564, hasil uji t berpengaruh nyata pada tingkat kepercayaan 99 persen. Hal ini menunjukkan bahwa kepuasan kerja berpengaruh nyata terhadap kenaikan kinerja pelayanan. Berarti setiap kenaikan kepuasan kerja sebesar 1 persen akan menaikkan kinerja pelayanan pada mahasiswa sebesar 0,564 persen. Kepuasan kerja merupakan sesuatu yang bersifat individual. Setiap individu memilki tingkat kepuasan yang berbeda sesuai dengan sistem nilai yang berlaku pada dirinya. Kepuasan kerja adalah keadaan emosional karyawan yang menyenangkan atau tidak menyenangkan terhadap tugas atau pekerjaan yang telah dibebani. Kepuasan kerja adalah sikap umum terhadap pekerjaan seseorang yang menunjukkan perbedaan antara jumlah penghargaan yang diterima pekerja dan jumlah seharusnya mereka terima. Kepuasan kerja terhadap kinerja karyawan menunjukkan bahwa kepuasan kerja berpengaruh signifikan terhadap kinerja karyawan. Kepuasan kerja berpengaruh terhadap kinerja, loyalitas karyawan dan perputaran kerja karyawan. Karyawan yang mempunyai kepuasan terhadap pekerjaannya sudah tentu memiliki loyalitas terhadap perusahaan, dan akan melakukan pekerjaan yang dibebankan kepadanya dengan penuh tanggung jawab (Zahara dan Hidayat, 2017). Hasil penelitian Santhi dan Hartati (2017), menyatakan bahwa terdapat pengaruh positif dan signifikan antara kinerja karyawan terhadap kepuasan kerja dan kualitas pelayanan terhadap kinerja karyawan. Demikian juga hasil penelitian Bulkia (2018), menyatakan kualitas pelayanan dalam hal ini kinerja pelayanan C) 2020 STIE TDN. All rights reserved

Corresponding Author: 
berpengaruh secara signifikan dan positif terhadap kepuasan mahasiswa di semua bagian pelayanan yang ada di Universitas Islam Kalimantan (Uniska) Muhammad Arsyad Al Banjary Banjarmasin. Sedangkan hasil penelitian Ilyas (2014), menyatakan tingkat kepuasan mahasiswa yang mengikuti kuliah Pendidikan Agama Islam terhadap layanan akademik yang diberikan oleh lembaga menunjukan kecenderungan sangat memuaskan. Hal ini mengindikasikan kinerja pelayanan dalam memberikan layanan kepada mahasiswa sangat memuaskan.

\section{KESIMPULAN DAN SARAN Kesimpulan}

Berdasarkan hasil dan pembahasan maka dapat disimpulkan kepercayaan dan kepuasan kerja secara bersama-sama berpengaruh nyata terhadap kinerja pelayanan pada mahasiswa di Universitas Muslim Maros.

\section{Saran}

Perlu peningkatan dan perbaikan secara keseluruhan dari elemen pelayanan pendidikan di Universitas Muslim Maros. Kualitas pelayanan hanya bisa terwujud apabila terjalin kerjasama yang baik dari semua pihak dan harus dilakukan evaluasi secara berkesinambungan.

\section{DAFTAR PUSTAKA}

Ambartiasari, G., Lubis, AR., dan Chan, S., 2017. Pengaruh
Kualitas Pelayanan, Kepercayaan dan Fasilitas Kampus Terhadap Kepuasan dan Dampaknya kepada Loyalitas Mahasiswa Politeknik Indonesia Venezuela. Jurnal Manajemen dan Inovasi. 8 (3) : 12 - 23.

Arifin, S., 2011. Pengaruh Kepercayaan, Fasilitas dan Kualitas Pelayanan Terhadap Kepuasan Konsumen pada Hotel Jepara Indah. Jurnal Dinamika Ekonomi \& Bisnis. 8 (1) : 67 - 78 .

Bhakti, YB., dan Rahmawati, EY., 2017. Indeks Kepuasan Mahasiswa Terhadap Pelayanan Program Studi Pendidikan Matematika. Jurnal Formatif. 7 (3) : 272 285.

Bulkia, S., 2018. Pengaruh Kualitas Pelayanan Terhadap Kepuasan Mahasiswa. AtTadbir: Jurnal Ilmiah Manajemen. 2 (1) : 49 - 58.

Dafroyati, Y., 2016. Kepuasan Mahasiswa Terhadap Kinerja Dosen dalam Pembelajaran pada Jurusan dan Program Studi di Lingkup Poltekkes Kemenkes Kupang Tahun 2014. Jurnal Info Kesehatan. 14 (1) : 1136 - 11.

Dedeh, 2017. Analisis Tingkat Kepuasan Mahasiswa Terhadap Kinerja Dosen Program Studi Pendidikan Akuntansi FKIP Universitas Galuh. Jurnal Ilmiah Edukasi. 5 (2) : 121 - 129. 
Edastama, P., 2014. Pengaruh Kualitas Service Terhadap Kepuasan, Kepercayaan, dan Kecenderungan Berperilaku Mahasiswa pada Perguruan Tinggi di Jakarta. Jurnal Manajemen dan Pemasaran Jasa. 7 (1) : 129 - 152.

Elrado, HM., Kumadji, S., dan Yulianto, E., 2014. Pengaruh Kualitas Pelayanan Terhadap Kepuasan, Kepercayaan dan Loyalitas (Survei pada Pelanggan yang Menginap di Jambuluwuk Batu Resort Kota Batu). Jurnal Administrasi Bisnis. 15 (2) : 1 - 9 .

Guspul, A., 2014. Pengaruh Kualitas Pelayanan dan Kepercayaan Terhadap Kepuasan Nasabah (Studi Kasus pada Nasabah Kospin Jasa Cabang Wonosobo). Jurnal PPKM UNSIQ. I : 40 - 54.

Hidayati, A., Fudholi, A., dan Sumarni, 2014. Analisis Kepuasan Mahasiswa Terhadap Kualitas Pelayanan Tenaga Administratif di Fakultas Farmasi Universitas Ahmad Dahlan Yogyakarta. Jurnal Pharmaçiana. 4 (1) : 59 $-64$.

Ilyas, 2014. Tingkat Kepuasan Mahasiswa Terhadap Layanan Akademik Dosen Pendidikan Agama Islam (Penelitian pada Mahasiswa Semester II Fakultas Ilmu Pendidikan Universitas Negeri Semarang). Jurnal
Penelitian Pendidikan. 31 (2) : 155 - 159 .

Kasmari dan Marlien, RA., 2018. Tingkat Kepuasan Mahasiswa Terhadap

Kualitas Pelayanan pada Universitas Stikubank

Semarang. Jurnal Dinamika Teknik. XI (1) : 22 - 38.

Kawulur, HR., 2017. Kinerja Pelayanan Akademik Di Fakultas Ekonomi Universitas Negeri Manado Dengan Model Balanced Score Card. Tasharruf : Journal Economic and Business of Islam. 2 (1) : 40 61.

Laely, N., 2016. Analisis Pengaruh Kepercayaan dan Harga Terhadap Loyalitas Pelanggan Dimediasi Kepuasan pada PT. Telkomsel di Kota Kediri. Jurnal Ilmu Ekonomi \& Manajemen. 3 (2) : 61 - 74.

Mardah, S., 2018. Analisis Kualitas Pelayanan dan Kepercayaan Terhadap Kepuasan Mahasiswa pada Biro Akademik dan Kemahasiswaan Uniska MAB Banjarmasin. Jurnal Ilmiah Ekonomi Bisnis. 4 (1) : 001 013.

Nurhadi, dan Azis, A., 2018. Pengaruh Kualitas Pelayanan Terhadap Kepercayaan dan Kesetiaan Konsumen. Jurnal Economia. 14 (1) : 89 - 98. 
Nyavon, P., 2017. Pengaruh Kinerja

Dosen Dengan Motivasi

Belajar pada Mahasiswa

Prodi Sosiatri Fakultas Ilmu

Sosial dan Ilmu Politik

Universitas Mulawarman

Samarinda. Jurnal

Psikoborneo. 5 (2) : 137 146.

Rinala, IN, Yudana, IM., dan Natajaya, IN., 2013. Pengaruh Kualitas

Pelayanan Akademik

Terhadap Kepuasan dan Loyalitas Mahasiswa pada Sekolah Tinggi Pariwisata Nusa Dua Bali. e-Journal Program Pascasarjana Universitas Pendidikan Ganesha. $4: 1$ - 12.

Safiuddin, dan Sunarsih, 2016. Pengaruh Kualitas Pelayanan terhadap Kepuasan Mahasiswa UIN Sunan Kalijaga Yogyakarta. Jurnal Az Zarqa. 8 (2) : 175 217.

Sahanggamu, S., Mananeke, L., dan Sepang, J., 2015. Analisis Kualitas Layanan, Servicescape dan Kepercayaan Terhadap Kepuasan Nasabah pada PT. Bank Sinarmas Bitung. Jurnal EMBA. 3 (1) : 1084 - 1095.
Santhi, NH., dan Hartati, W., 2017. Pengaruh Kualitas Pelayanan Terhadap Kinerja dan Kepuasan Mahasiswa (Studi Kasus pada Mahasiswa STIA Muhammadiyah Selong). Jurnal Humanitas. 4 (1) : 1 15.

Sugiyono, 2005. Metode Penelitian Bisnis. Cetakan Kedelapan. CV. Alfabeta Bandung.

Sutrisno, E., dan Maryono, J., 2016. Pengaruh Kualitas Pepelayanan dan Kinerja Pegawai Terhadap Kepuasan Masyarakat (Keluarganya Warga Binaan Pemasyarakatan) pada Lembaga Pemasyarakatan Kelas IIB Slawi. Jurnal Multplier. 1 (1) : 66 - 83.

Suyanto, MA., dan Setiawan, SR., 2019. Model Kepercayaan Mahasiswa. Gorontalo Management Research. 2 (2) : 117 - 131.

Zahara, RN., dan Hidayat, H., 2017. Pengaruh Kepuasan dan Disiplin Kerja Terhadap Kinerja Karyawan Bank di Kota Batam. Journal of Applied Managerial Accounting. 1 (2) : 150 - 156. 